\title{
Antiviral Effect of Retro-2.1 against Herpes Simplex Virus Type 2 In Vitro
}

\author{
Wenwen Dai ${ }^{1}, \mathrm{Yu} \mathrm{Wu}^{2}$, Jinpeng $\mathrm{Bi}^{1}$, Jingyu Wang${ }^{1}$, Shuai Wang ${ }^{1}$, Wei Kong ${ }^{1,3}$, Julien Barbier ${ }^{2}$, \\ Jean-Christophe Cintrat ${ }^{2}$, Feng Gao ${ }^{1,3}$, Zhengran Jiang ${ }^{4}$, Daniel Gillet ${ }^{2 *}$, Weiheng Su, ${ }^{1,3 *}$, and Chunlai Jiang ${ }^{1,3 *}$ \\ ${ }^{1}$ National Engineering Laboratory for AIDS Vaccine, School of Life Sciences, Jilin University, Changchun 130012, P.R. China \\ ${ }^{2}$ Joliot, CEA, LabEx LERMIT, Université Paris-Saclay, F-91191 Gif Sur Yvette, France \\ ${ }^{3}$ Key Laboratory for Molecular Enzymology and Engineering of the Ministry of Education, School of Life Sciences, Jilin University, \\ Changchun 130012, P.R. China \\ ${ }^{4}$ Maclay School, Tallahassee, FL 32312, USA
}

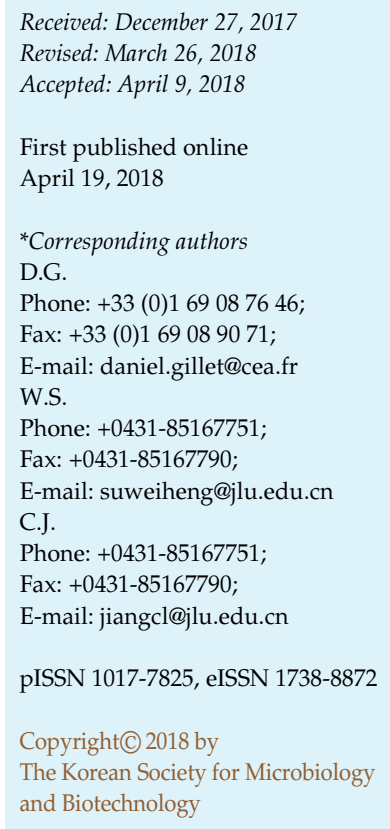

Herpes simplex virus type 2 (HSV-2) infection has been a public health concern worldwide. It is the leading cause of genital herpes and a contributing factor to cervical cancer and human immunodeficiency virus (HIV) infection. No vaccine is available yet for the treatment of HSV2 infection, and routinely used synthetic nucleoside analogs have led to the emergence of drug resistance. The small molecule Retro- $2^{\text {cycl }}$ has been reported to be active against several pathogens by acting on intracellular vesicle transport, which also participates in the HSV-2 lifecycle. Here, we showed that Retro-2.1, which is an optimized, more potent derivative of Retro- $2^{\text {cycl }}$, could inhibit HSV-2 infection, with $50 \%$ inhibitory concentrations of $5.58 \mu \mathrm{M}$ and $6.35 \mu \mathrm{M}$ in cytopathic effect inhibition and plaque reduction assays, respectively. The cytotoxicity of Retro- 2.1 was relatively low, with a 50\% cytotoxicity concentration of $116.5 \mu \mathrm{M}$. We also preliminarily identified that Retro-2.1 exerted the antiviral effect against HSV-2 by a dual mechanism of action on virus entry and late stages of infection. Therefore, our study for the first time demonstrated Retro-2.1 as an effective antiviral agent against HSV-2 in vitro with targets distinct from those of nucleoside analogs.

Keywords: Herpes simplex virus type 2, Retro-2.1, antiviral effect, entry, late stage, vesicle transport

\section{Introduction}

Herpes simplex virus type 2 (HSV-2) is a single, large, double-stranded DNA enveloped virus within the family Herpesviridae [1]. HSV-2 infection is sexually transmitted, with a lifelong latency in populations worldwide, and is the leading cause of genital herpes characterized by vesicles or ulcers on the reproductive organs [2]. HSV-2 infection is also a risk factor for cervical cancer and the acquisition and transmission of human immunodeficiency virus (HIV) [3-5]. Based on the global estimates of 536 million infected people with an annual incidence of 23.6 million cases, HSV-2 infection has been a public health concern worldwide [6].

Even though many attempts have been made to develop vaccines against HSV-2, none was reported to be effective in clinical trials [7]. Synthetic nucleoside analogs targeting viral DNA polymerase, including acyclovir, valaciclovir, famciclovir, and penciclovir, are routinely used as a standard treatment for HSV-2 infection [8]. However, longterm use of nucleoside analogs has led to drug resistance, implicating an increase of recurrence and treatment failure. Thus, the efficacy of existing antiviral management has been limited [9]. Although some non-nucleoside analog inhibitors of HSV-2 have been developed, most of them were not approved owing to adverse effects [10]. Therefore, safe 
and effective antiviral agents against HSV-2 with targets distinct from those of nucleoside analogs are urgently needed.

Retro- $2^{\text {cycl }}$ was first reported to be a retrograde trafficking inhibitor active against ricin and Shiga toxins, changing the intracellular distributions of syntaxin 5 and syntaxin 6 to a lesser extent [11]. Syntaxins are members of the SNARE (soluble $N$-ethylmaleimide-sensitive factor attachment protein receptor) family of membrane proteins that mediate intracellular vesicle transport [12]. Subsequently, Retro- ${ }^{\text {cycl }}$ was also demonstrated to be active against intracellular infectious pathogens. Cell infections by adeno-associated viruses, polyomaviruses, papillomaviruses, and poxviruses were inhibited by Retro- $2^{\text {cycl }}$ via similar mechanisms related to that against toxins involving redistributions of syntaxins and alterations of retrograde transport vesicles between endosomes and the Golgi apparatus [13-18]. Cell infections by Ebola virus, Marburg virus, Chlamydia trachomatis, Simkania negevensis and Leishmania were also inhibited by Retro- $2^{\text {cycl }}$ by interfering with virus entry or formation of the bacteria or parasite's intracellular vacuoles [19-21]. In vivo studies demonstrated that Retro- $2^{\text {cycl }}$ protected mice from ricin, Shiga toxin-producing E. coli O104:H4, vaccinia virus, and Leishmania challenges [11, 16, $20,22]$. In our most recent published study, Retro- $2^{\text {cycl }}$ showed effective antiviral activity against enterovirus 71 in cell cultures and significantly protected $90 \%$ of newborn mice from enterovirus 71 inoculation by blocking progeny virus release [23]. Taken together, the findings thus far demonstrate that Retro- $2^{\text {cycl }}$ exerts inhibitory effects on these pathogens by acting on intracellular processes associated with vesicle transport. Retro-2.1 is an optimized, more potent derivative of Retro- $2^{\text {cycl }}$ [24]. Thus, it is effective in redistributing syntaxins and inhibiting intracellular vesicle transport as well.

HSV-2 infection begins with initial binding to the cell, followed by entry via membrane fusion or endocytosis. Virus DNA replication, protein synthesis, and capsid assembly take place successively, followed by release of filled capsids from the nucleus to the cytoplasm. Subsequently, the filled capsids acquire an envelope and an outer vesicular membrane by budding into vesicles derived from the transGolgi network. Finally, virus-containing vesicles move to and fuse with the cell membrane to release enveloped viruses [25-27]. Together, the facts that intracellular vesicle transport plays a major role in the HSV-2 lifecycle and is a main target for Retro-2.1 provide a rationale for testing the potential antiviral activity of Retro-2.1 against HSV-2.

In this study, we investigated the antiviral activity of Retro-2.1 against HSV-2 in cell cultures, and clarified the preliminary mechanisms. Retro-2.1 was found to protect cells effectively from HSV-2 infection by inhibiting virus entry and late stages of the HSV-2 lifecycle.

\section{Materials and Methods}

\section{Cells, Virus, and Compounds}

African green monkey kidney cells (Vero cells) were obtained from ATCC (Cat. No. CCL-81) and grown in Dulbecco's modified Eagle's medium (DMEM; Invitrogen, USA) supplemented with $10 \%$ fetal bovine serum (FBS; Invitrogen, USA) (DMEM-10\% FBS) at $37^{\circ} \mathrm{C}$ with $5 \% \mathrm{CO}_{2}$.

HSV-2 strain G was obtained from ATCC (Cat. No. VR-734) (KU310668). Its propagation and titer determination were performed in Vero cells.

Retro-2.1 (6-fluoro-1-methyl-2-(5-(2-methylthiazol-4-yl)thiophen2-yl)-3-phenyl-2,3-dihydroquinazolin-4(1H)-one) (Fig. 1) with a purity higher than $95 \%$ determined by LC/MS was synthesized in-house [24]. Chloroquine and acyclovir, which were used as positive control drugs as reported, with purities higher than $98 \%$ as determined by HPLC, were purchased from Meilun Biotech Co., Ltd. (China) [28, 29]. The compounds were dissolved in dimethyl sulfoxide as stocks and diluted with DMEM supplemented with $2 \%$ FBS (DMEM- $2 \%$ FBS) to working concentrations.

\section{Cytotoxicity and Cytopathic Effect (CPE) Inhibition Assays}

Vero cells were seeded in 96-well plates to $90 \%$ confluency. In the cytotoxicity assay, the cells were treated with serially diluted compounds for $72 \mathrm{~h}$ before analysis. In the CPE inhibition assay, the cells were treated with serially diluted Retro-2.1 from $5 \mathrm{~h}$ before infection with HSV-2 (MOI $=0.04$, which was determined to cause appropriate CPE (100\%) and cell viability reduction (60\%) on Vero cells after infection for $72 \mathrm{~h}$ ), or with serially diluted chloroquine or acyclovir from $5 \mathrm{~h}$ before or at the same time with infection, respectively. The cells were further incubated for $72 \mathrm{~h}$ in the presence of the compounds in the medium before analysis. At the end of both assays, the cell viability was measured using the Cell Titer-Glo reagent (Promega, USA) [30] and quantified with the VICTOR X2 (PerkinElmer, USA). The cytotoxicity and CPE inhibition rate were respectively measured by the following equations: cell viability $(\%)=\left(T_{1} / C\right) \times 100 \%$ and CPE inhibition

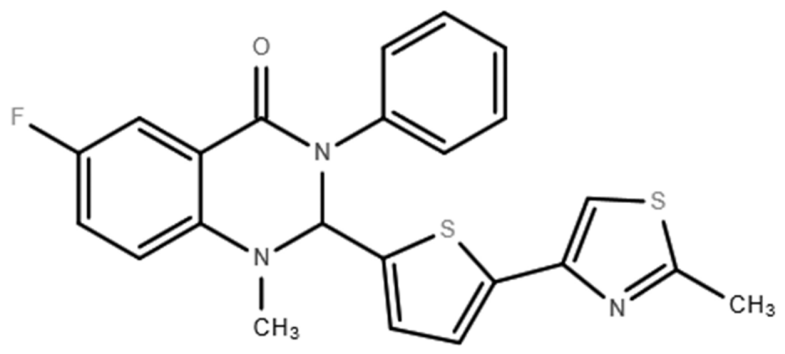

Fig. 1. Chemical structure of Retro-2.1. 
$(\%)=\left(T_{2}-V\right) /(C-V) \times 100 \%$, where $C, V, T_{1}$, and $T_{2}$ are luminescenceintensities of the cell control, virus control, and compound-treated uninfected and infected cells, respectively. The $50 \%$ cytotoxicity concentration $\left(\mathrm{CC}_{50}\right)$ and $50 \%$ inhibitory concentration $\left(\mathrm{IC}_{50}\right)$ of the compounds were calculated by regression analysis [31].

\section{Plaque Reduction Assay}

Vero cells seeded in 12-well plates and grown as monolayers were treated with serially diluted Retro-2.1 from $5 \mathrm{~h}$ before infection with HSV-2 for $1 \mathrm{~h}$ (50-100 PFU, which was determined to ensure appropriate numbers of plaques would form in the plates to be counted accurately), followed by replacement of the inoculum with DMEM-2\% FBS-1\% low-melting agarose containing Retro-2.1 at corresponding concentrations. The cells were further incubated for $72 \mathrm{~h}$ until plaques formed, fixed with $4 \%$ paraformaldehyde, and stained with $0.5 \%$ crystal violet before the plaque numbers were counted. The plaque inhibition rate was calculated by the following equation: plaque inhibition $(\%)=[1-$ (plaque number $\left.)_{\mathrm{T}} /(\text { plaque number })_{\mathrm{V}}\right] \times 100 \%$, where (plaque number $)_{\mathrm{T}}$ and (plaque number $)_{\mathrm{V}}$ are the plaque numbers of Retro2.1-treated infected cells and virus control, respectively. The $\mathrm{IC}_{50}$ of Retro-2.1 was calculated by regression analysis [31].

\section{Western Blot Assay}

Cell samples were lysed in RIPA buffer (Beyotime Biotech Co., Ltd., China) and cleared by centrifugation. Proteins in the cell lysates were separated by SDS-PAGE and electroblotted onto nitrocellulose membranes. The membranes were blocked with $3 \%$ non-fat milk for $1 \mathrm{~h}$ and subsequently incubated with an antiHSV-2 VP5 (major capsid protein of HSV-2 [32]) (EastCoast Bio, USA) or an anti- $\beta$-tubulin mouse monoclonal antibody (Covance, USA) for $2 \mathrm{~h}$, followed by reaction with an alkaline phosphatase (AP)-labeled anti-mouse IgG antibody (SouthernBiotech, USA) for $1 \mathrm{~h}$. The membranes were finally blotted using the AP substrate.

\section{Quantitative Polymerase Chain Reaction (qPCR) Assay}

The HSV-2 DNA was extracted using the Ezup Column Virus DNA Purification Kit (Sangon Biotech Co., Ltd., China), followed by further quantification with the TransStart ${ }^{\circledR}$ Top Green qPCR SuperMix (TransGen Biotech Co., Ltd., China) and gG-specific primers using the Bio-Rad CFX96 system (Bio-Rad, USA).

\section{Time of Retro-2.1 Addition Assay}

Vero cells were seeded in 24-well plates to $90 \%$ confluency. In the antiviral activity assay of the compounds against HSV-2 based on viral protein and DNA content, the cells were treated with $12.5 \mu \mathrm{M}$ Retro-2.1 from $5 \mathrm{~h}$ before infection with HSV-2 for $1 \mathrm{~h}$ (MOI $=1$ [33]), or with $15 \mu \mathrm{M}$ chloroquine or $1 \mu \mathrm{M}$ acyclovir from $5 \mathrm{~h}$ before or at the same time with infection, followed by replacement of the inoculum with the compounds at corresponding concentrations. The cells were further incubated until $18 \mathrm{~h}$ postinfection to ensure a single lifecycle without obvious CPE before the HSV-2 protein and DNA contents in the cell cultures were measured [34]. Besides this, HSV-2 titers in the cell cultures were also measured by the endpoint dilution assay. The $50 \%$ tissue culture infectious dose $\left(\mathrm{TCID}_{50}\right)$ was calculated by the Reed and Muench method

In the effective stage assay of Retro-2.1 against HSV-2, a time of Retro-2.1 addition assay was performed as reported, with some modifications [35]. The cells were treated with $12.5 \mu \mathrm{M}$ Retro-2.1 for $5 \mathrm{~h}$ before infection (pre: $-5-0 \mathrm{~h}$ ), at the same time with infection (simultaneous: $0-1 \mathrm{~h}$ ), or during periods post-infection (early post: $1-6 \mathrm{~h}$; late post: $6-18 \mathrm{~h}$ ) to determine whether Retro2.1 could exert an antiviral effect against HSV-2 through a preventive effect on the cells, an inhibitory effect on virus binding or entry, on virus replication or late stages of infection. Moreover, the virucidal effect of Retro-2.1 on HSV-2 directly was determined by the pretreatment of HSV-2 with Retro-2.1 at the same concentration as in other procedures at $4^{\circ} \mathrm{C}$ for $5 \mathrm{~h}$ before infection (direct). Within all procedures, the infection was performed by addition of HSV-2 (MOI = 1 [33]) during $0-1 \mathrm{~h}$ (except for the direct procedure, in which the cells were infected with HSV-2 pretreated with Retro-2.1). The HSV-2 DNA content as well as titers in the cell cultures were measured at $18 \mathrm{~h}$ post-infection [34].

\section{Binding and Entry Assays}

Vero cells were seeded in 24-well plates to $90 \%$ confluency and treated as previously reported in a study on effects of Dynasore on HSV-2 binding and entry [36]. Briefly, the cells were treated with $12.5 \mu \mathrm{M}$ Retro- 2.1 at $37^{\circ} \mathrm{C}$ for $5 \mathrm{~h}$ before infection, or with $15 \mu \mathrm{M}$ chloroquine or $1 \mu \mathrm{M}$ acyclovir for $5 \mathrm{~h}$ before or at the same time with infection. For the binding assay, the pre-chilled cells were incubated with HSV-2 (50-100 PFU) at $4^{\circ} \mathrm{C}$ for $2 \mathrm{~h}$, followed by removal of unbound viruses by washing. The cells were then covered with DMEM-2\% FBS-1\% low-melting agarose and further incubated for $72 \mathrm{~h}$ until plaques formed, fixed with $4 \%$ paraformaldehyde, and stained with $0.5 \%$ crystal violet before the plaque numbers were counted. For the entry assay, the cells in the binding assay were further incubated at $37^{\circ} \mathrm{C}$ for $1 \mathrm{~h}$ to allow virus entry after removal of unbound viruses. The cells were then treated with citrate-buffer ( $\mathrm{pH}$ 3.0) for $1 \mathrm{~min}$ and washed by PBS, followed by the plaque number assay.

\section{Immunofluorescence Assay}

Cells grown on glass coverslips were treated and infected as described for the binding and entry assays to study effects of Retro-2.1, except that the MOI was determined to be 10 to enhance the fluorescence intensity. At the end of the entry assay, the cells were fixed with $4 \%$ paraformaldehyde and treated with $0.2 \%$ Triton X-100 for $15 \mathrm{~min}$, respectively, followed by blocking with $1 \%$ bovine serum albumin and incubation with an anti-HSV-2 VP5 mouse monoclonal antibody for 1 and $2 \mathrm{~h}$, respectively. Subsequently, the cells were reacted with a goat anti-mouse antibody conjugated with FITC (Bioss Biotech Co., Ltd., China) for $1 \mathrm{~h}$. DAPI (KeyGEN Biotech Co., Ltd., China) was used to stain the nuclei. Fluorescence 
A

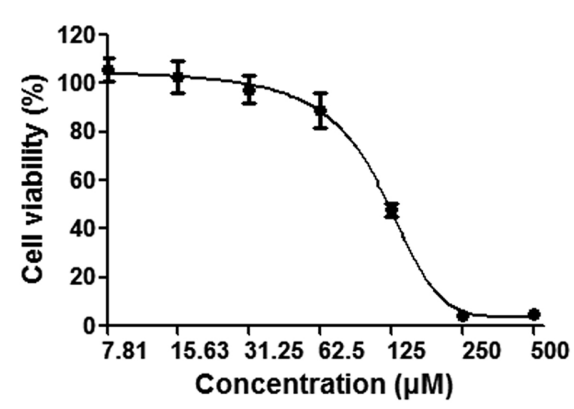

B

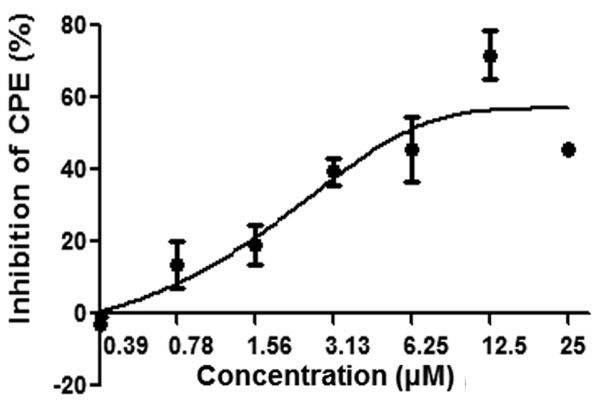

C

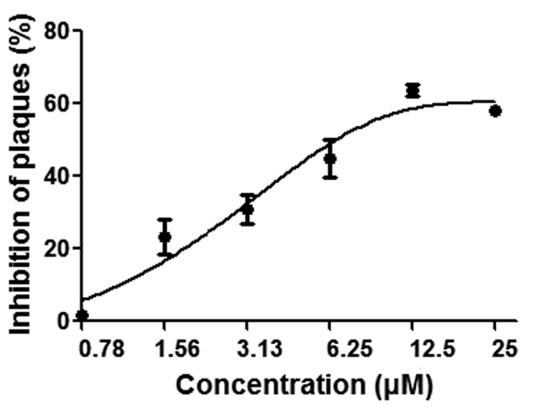

Fig. 2. Cytotoxicity and antiviral activity of Retro-2.1 against HSV-2.

(A) Vero cells were treated with serially diluted Retro- 2.1 for $72 \mathrm{~h}$, and then the cell viability was measured and compared with that of the cell control. (B) Vero cells were treated with serially diluted Retro-2.1 from $5 \mathrm{~h}$ before infection with HSV-2 (MOI = 0.04) and further incubated for $72 \mathrm{~h}$ in the presence of Retro-2.1, and then the cell viability was measured to calculate the rate of inhibition of the cytopathic effect (CPE). (C) Vero cells were treated with serially diluted Retro-2.1 from $5 \mathrm{~h}$ before infection with HSV-2 (50-100 PFU) for $1 \mathrm{~h}$, followed by replacement of the inoculum with DMEM-2\% FBS-1\% low-melting agarose containing Retro-2.1 at corresponding concentrations, and then the plaque numbers were counted to calculate the rate of inhibition of the plaques.

was recorded using a Zeiss LSM 710 laser scanning confocal microscope (Zeiss, Germany).

\section{Late Stage Assays}

Vero cells were seeded in 24-well plates to $90 \%$ confluency and infected with HSV-2 (MOI = 1 [33]) during 0-1 h, and then treated with $12.5 \mu \mathrm{M}$ Retro-2.1 during 6-18 h, or with chloroquine and acyclovir as described in the antiviral activity assay. Intracellular and extracellular viruses were collected from the cells (by freezethaw cycles) and the cell supernatants, and total viruses were collected from the cell cultures by freeze-thaw cycles, respectively, followed by titer determination by the endpoint dilution assay at $6,8,10,12$, and $18 \mathrm{~h}$ post-infection. The $\mathrm{TCID}_{50}$ was calculated by the Reed and Muench method.

\section{Statistical Analysis}

All experiments were conducted in triplicate and repeated three times independently. A one-way ANOVA test was used for statistical analysis to compare differences between the test group and the virus control group. Statistical significance represented by asterisks is marked correspondingly in the figures $\left({ }^{*} p<0.05\right.$, $\left.{ }^{* *} p<0.01,{ }^{* * *} p<0.001\right)$.

\section{Results}

\section{Reduced Cytopathic Effect and Plaque Formation Were Detected in Retro-2.1-Treated Cells}

The cytotoxicity of Retro-2.1 was evaluated before detecting its antiviral activity. As shown in Fig. 2A and Table 1, Retro-2.1 showed nearly no cytotoxic effect on Vero cells at concentrations effective against HSV-2 infection, with a $\mathrm{CC}_{50}$ value of $116.5 \mu \mathrm{M}$. Subsequently, the antiviral activity of Retro-2.1 against HSV-2 in Vero cells was evaluated by CPE inhibition and plaque reduction assays, respectively. As Retro-2.1 changed the intracellular distributions of syntaxin 5 and syntaxin 6 , which regulate the transport of intracellular vesicles, and syntaxin 6 could be redistributed significantly only when the treatment reached $4 \mathrm{~h}$, Retro-2.1 was added to the cells $5 \mathrm{~h}$ prior to infection and left throughout the process to ensure sufficient action on the cells [11]. As shown in Figs. 2B and 2C and Table 1, Retro-2.1 inhibited HSV-2 infection in a dose-dependent manner in both $\mathrm{CPE}$ inhibition and plaque reduction assays, and showed similar $\mathrm{IC}_{50}$ values of 5.58 and $6.35 \mu \mathrm{M}$, respectively. The antiviral activity of Retro2.1 was also expressed as a selective index (SI), with a value of 20.88, which was higher than that of the positive control drug chloroquine. Therefore, Retro-2.1 was demonstrated to be a safe and effective antiviral agent against HSV-2 in vitro that could protect Vero cells from HSV-2 infection.

Table 1. Cytotoxicity and antiviral activity of various compounds against HSV-2 in Vero cells.

\begin{tabular}{lcccc}
\hline & Cytotoxicity & \multicolumn{3}{c}{ Antiviral activity } \\
\hline Compounds & $\mathrm{CC}_{50}(\mu \mathrm{M})$ & $\mathrm{IC}_{50}{ }^{\mathrm{a}}(\mu \mathrm{M})$ & $\mathrm{IC}_{50}{ }^{\mathrm{b}}(\mu \mathrm{M})$ & $\mathrm{SI}^{\mathrm{c}}$ \\
\hline Retro-2.1 & 116.50 & 5.58 & 6.35 & 20.88 \\
Chloroquine & 15.67 & 1.86 & $\mathrm{ND}$ & 8.42 \\
Acyclovir & $>1,000$ & 0.82 & $\mathrm{ND}$ & 1219.51 \\
\hline
\end{tabular}

${ }^{\mathrm{a} C}$ Concentration at which the compound CPE inhibition rate reaches $50 \%$.

${ }^{\mathrm{b}}$ Concentration at which the compound plaque reduction rate reaches $50 \%$. 'Selective index (SI) value represents the ratio of $\mathrm{CC}_{50} / \mathrm{IC}_{50}$ for each compound. Results are presented as the mean values obtained from three independent experiments. ND, not determined. 
A

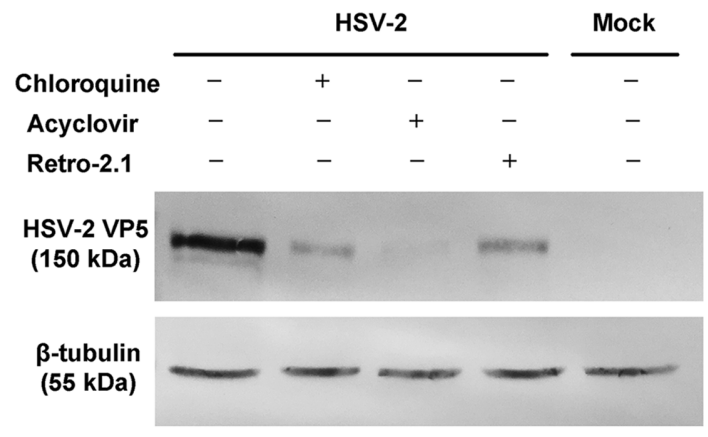

B

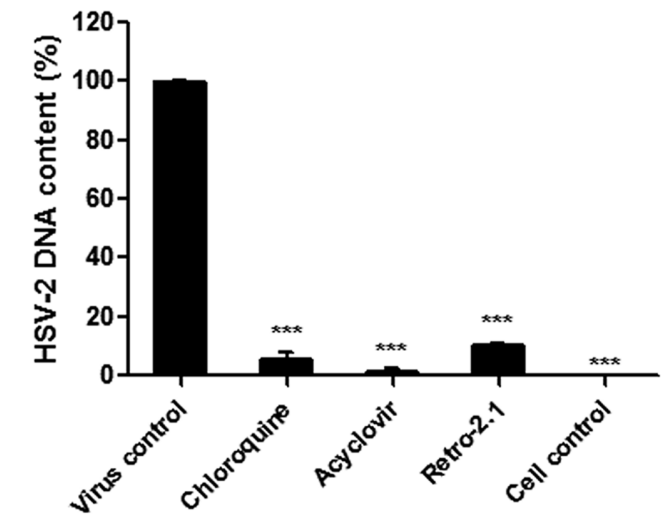

C

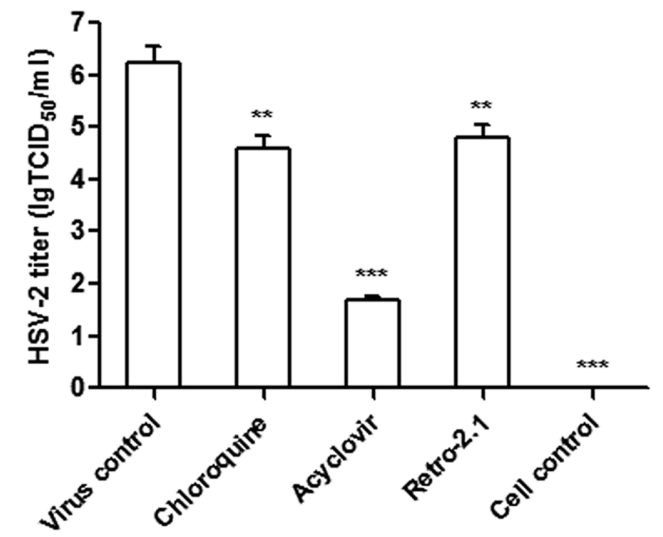

Fig. 3. Effects of Retro-2.1 on HSV-2 protein and DNA content as well as virus titers.

Vero cells were treated with $12.5 \mu \mathrm{M}$ Retro- 2.1 from $5 \mathrm{~h}$ before infection with HSV-2 for $1 \mathrm{~h}(\mathrm{MOI}=1)$, or with $15 \mu \mathrm{M}$ chloroquine or $1 \mu \mathrm{M}$ acyclovir from $5 \mathrm{~h}$ before or at the same time with infection, followed by replacement of the inoculum with the compounds at corresponding concentrations, and then the samples were collected at $18 \mathrm{~h}$ post-infection. (A) Proteins were extracted from the cell cultures, separated by SDS-PAGE, and analyzed by western blot assay using an anti-HSV-2 VP5 or an anti- $\beta$-tubulin antibody. (B) The HSV-2 DNA was extracted from the cell cultures and quantified by qPCR. (C) HSV-2 was collected from the cell cultures and subject to virus titer determination. Statistical significance was compared between the test group and the virus control group, where ${ }^{* *} p<0.01$ and ${ }^{* * *} p<0.001$
A

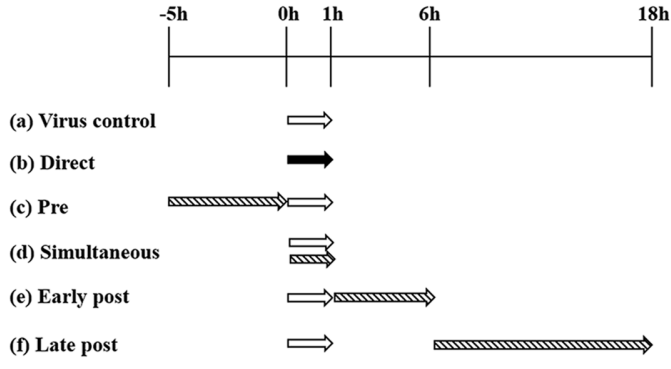

$\Longrightarrow$ HSV-2

B

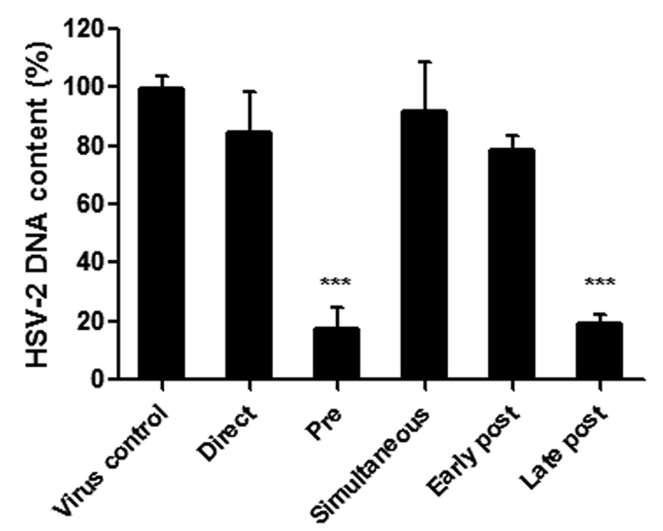

C

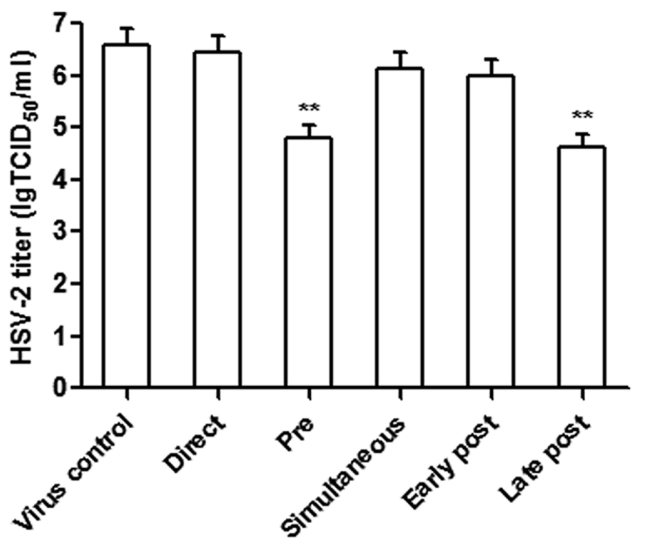

Fig. 4. Effects of Retro-2.1 on different stages of the HSV-2 lifecycle.

(A) HSV-2 (MOI = 1) and Retro-2.1 (12.5 $\mu \mathrm{M})$ treatment schemes in the time of Retro-2.1 addition assay. (B) HSV-2 DNA was extracted from the cell cultures and quantified by $\mathrm{qPCR}$ at $18 \mathrm{~h}$ post-infection. (C) HSV-2 was collected from the cell cultures and subjected to virus titer determination at $18 \mathrm{~h}$ post-infection. Statistical significance was compared between the test group and the virus control group, where ${ }^{* *} p<0.01$ and ${ }^{* * *} p<0.001$.

Reduced HSV-2 Protein and DNA Content as Well as Virus Titers Were Detected in Retro-2.1-Treated Cells

The antiviral activity of Retro-2.1 against HSV-2 was 
A

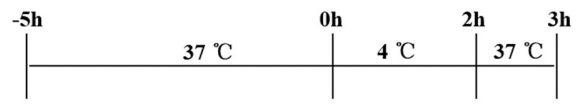

(a) Binding

(b) Entry

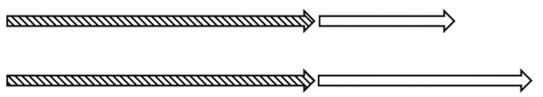

$\Longrightarrow$ HSV-2 Retro-2.1

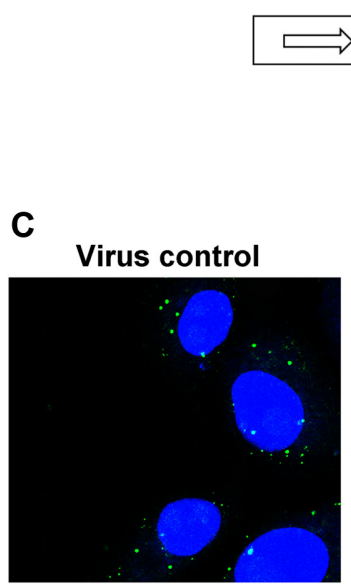

Retro-2.1

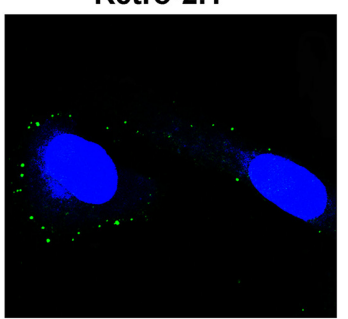

B

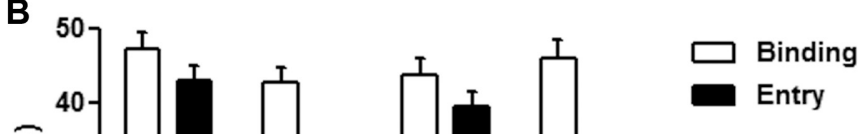

Fig. 5. Effects of Retro-2.1 on HSV-2 binding and entry.

(A) HSV-2 (50-100 PFU) and Retro-2.1 (12.5 $\mu \mathrm{M})$ treatment schemes in the binding and entry assays. Chloroquine $(15 \mu \mathrm{M})$ or acyclovir $(1 \mu \mathrm{M})$ was added at $5 \mathrm{~h}$ before or at the same time with infection. (B) At the end of the binding assay, the cells were covered with DMEM-2\% FBS- $1 \%$ lowmelting agarose and further incubated for $72 \mathrm{~h}$ until plaques formed, fixed with $4 \%$ paraformaldehyde, and stained with $0.5 \%$ crystal violet before the plaque numbers were counted. At the end of the entry assay, the cells were treated with citrate-buffer (pH 3.0) for 1 min and washed by PBS, followed by the plaque number assay. (C) Vero cells grown on glass coverslips were treated and infected as described in the binding and entry assays except that an MOI of 10 was used, and then immunofluorescence assay of the cells was performed at the end of the entry assay by incubation with an anti-HSV-2 VP5 mouse monoclonal antibody and reaction with a goat anti-mouse antibody conjugated with FITC (green), respectively. The nuclei were stained with DAPI (blue). Statistical significance was compared between the test group and the virus control group, where ${ }^{* *} p<0.01$ and ${ }^{* * *} p<0.001$.

further evaluated by biosynthesis of HSV-2 based on protein and DNA content as well as virus titers in a single replicative cycle without obvious $\mathrm{CPE}$ at $18 \mathrm{~h}$ post-infection [34]. As shown in Fig. 3, significant reductions in HSV-2 protein (monitored by VP5) and DNA content as well as virus titers were detected in Retro-2.1-treated cells as compared with the virus control. As the anti-HSV-2 targets of positive control drugs chloroquine and acyclovir are virus entry and replication [28, 29], they significantly reduced the HSV-2 protein and DNA content as well as virus titers as expected. Therefore, Retro- 2.1 was demonstrated to be an effective antiviral agent against HSV-2 in vitro that could cause reduced HSV-2 protein and DNA content as well as virus titers.

\section{Retro-2.1 Blocks HSV-2 Entry into Cells}

Having identified the antiviral potency of Retro-2.1 against HSV-2, the mechanisms were further investigated. 
A

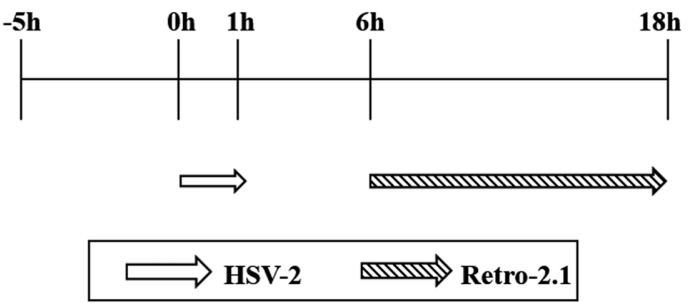

C

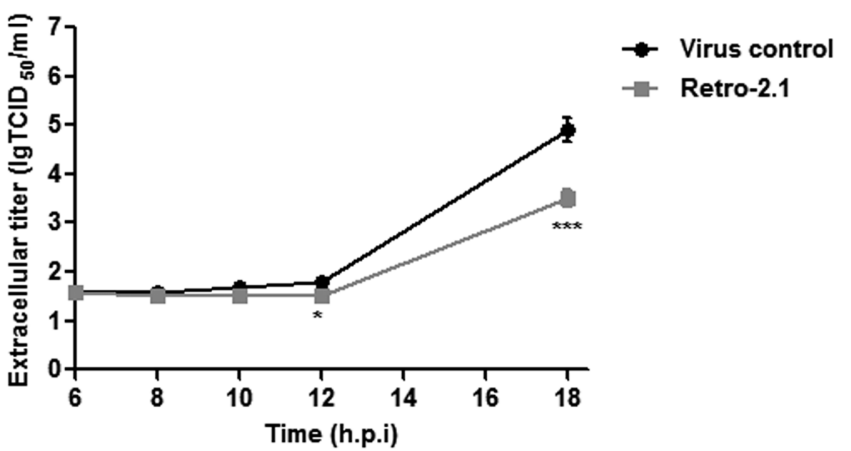

B

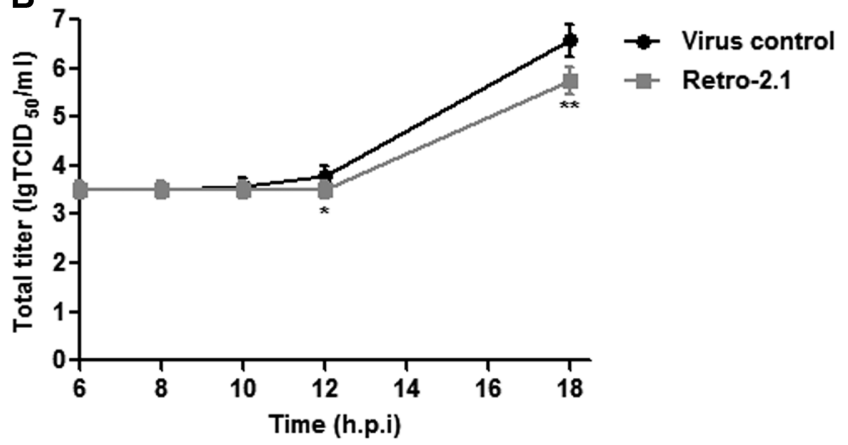

D

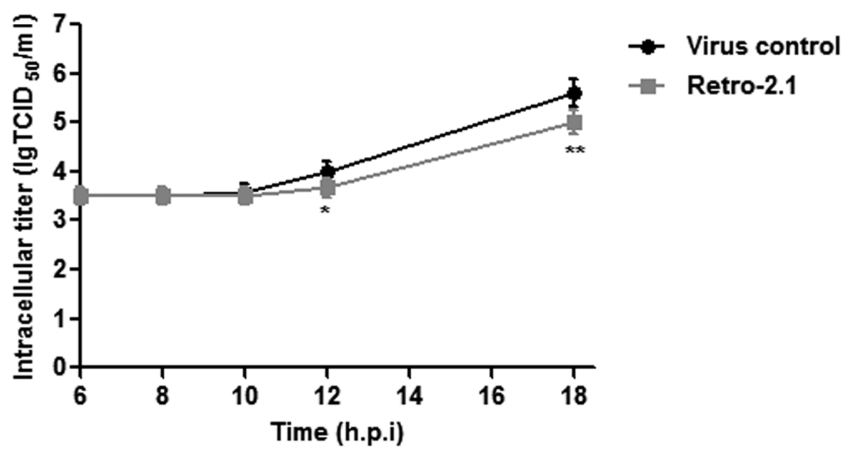

Fig. 6. Effects of Retro-2.1 on late stages of the HSV-2 lifecycle.

(A) HSV-2 $(\mathrm{MOI}=1)$ and Retro-2.1 $(12.5 \mu \mathrm{M})$ treatment schemes in the virus titer determination assay. Chloroquine $(15 \mu \mathrm{M})$ or acyclovir $(1 \mu \mathrm{M})$ was added from $5 \mathrm{~h}$ before or at the same time with infection. (B) Total viruses were collected from the cell cultures by freeze-thaw cycles and subjected to titer determination at 6, 8, 10,12, and $18 \mathrm{~h}$ post-infection (C) Extracellular viruses were collected from the cell supernatants and subjected to titer determination at $6,8,10,12$, and $18 \mathrm{~h}$ post-infection. (D) Intracellular viruses were collected from the cells by freeze-thaw cycles and subjected to titer determination at $6,8,10,12$, and $18 \mathrm{~h}$ post-infection. Statistical significance was compared between the test group and the virus control group, where ${ }^{*} p<0.05,{ }^{* *} p<0.01$, and ${ }^{* * *} p<0.001$.

A time of Retro-2.1 addition assay with different treatment schemes was first performed to determine stages of the HSV-2 lifecycle targeted by Retro-2.1 (Fig. 4A). The HSV-2 DNA content in the cell cultures was measured at $18 \mathrm{~h}$ post-infection [34]. As shown in Fig. 4, no significant difference in HSV-2 DNA content as well as virus titers was observed compared with virus control when Retro-2.1 was applied to the viruses only (direct), to the cells during infection (simultaneous), or during the early period postinfection (early post). It indicated that Retro-2.1 did not inactivate HSV-2 (direct) or affect the early stages of HSV-2 infection directly (simultaneous) and had no effect on HSV-2 replication (early post), which mainly takes place during 2-6 h post-infection [37, 38]. In contrast, the HSV-2 DNA content as well as virus titers was significantly reduced when the cells were treated with Retro-2.1 prior to infection (pre). It indicated that Retro-2.1 might act on the cells directly and thereby affect early events of the HSV-2 lifecycle as reported in previous studies on antiviral mechanisms of polysaccharide extracts from algal species and SPL-2999 against HSV-2 [39, 40]. The HSV-2 DNA content as well as virus titers was also significantly reduced when Retro-2.1 was present during 6-18 h post-infection (late post) (Fig. 4). It indicated that Retro-2.1 also played a role in the late stages of the HSV-2 lifecycle, which was confirmed later. As there was no toxic effect of Retro-2.1 on Vero cells at the concentration used, the inhibitory effect of Retro-2.1 against HSV-2 was not due to cytotoxicity.

To investigate which event in the early stages of the HSV-2 lifecycle was disrupted by Retro-2.1, virus binding and entry assays were performed at $4^{\circ} \mathrm{C}$ and $37^{\circ} \mathrm{C}$ individually after pretreatment of the cells with Retro-2.1 (Fig. 5A). As shown in Fig. 5B, Retro-2.1 inhibited virus entry rather than binding in the early stages of the HSV-2 
lifecycle. As the target of chloroquine is the HSV-2 entry process as well, we found as expected that entry of HSV-2 was also reduced by chloroquine [29]. The effects of Retro2.1 on HSV-2 binding and entry were further confirmed in an immunofluorescence assay performed at the end of the entry assay. As shown in Fig. 5C, HSV-2 fluorescence associated with the cells was not reduced by the treatment with the compounds, indicating that the compounds did not interfere with initial binding of HSV-2 to the cells. HSV-2 tended to be distributed in the area near or within the cell nuclei in the virus control or acyclovir-treated cells, whereas it was distributed in the periphery area around the cell membranes in Retro-2.1- or chloroquine-treated cells, indicating that Retro-2.1 and chloroquine inhibited HSV-2 entry into the cells. Therefore, Retro-2.1 was demonstrated to block HSV-2 entry into host cells as previously reported in a study on the inhibitory effect of Dynasore on HSV-2 entry rather than binding [36].

\section{Retro-2.1 Inhibits Late Stages of the HSV-2 Lifecycle}

To study the effects of Retro-2.1 on the late stages of the HSV-2 lifecycle, a virus titer determination assay was performed after the treatment of the cells with Retro-2.1 during $6-18 \mathrm{~h}$ post-infection (Fig. 6A). As shown in Fig. 6B, HSV-2 titers were significantly reduced with the treatment of Retro-2.1. On one hand, the results confirmed the inhibitory effect of Retro-2.1 on late stages of the HSV-2 lifecycle. On the other hand, as formations of both capsids and progeny infectious particles of HSV-2 gradually take place from $5 \mathrm{~h}$ post-infection [38], the results suggested that Retro-2.1 was most likely to affect progeny HSV-2 packaging in the late stages, as reported in a study on Nelfinavir against HSV-1 [41]. Besides this, the reduction rate of the slope of the replication kinetics curve of the extracellular HSV-2 titer was much more than that of the intracellular HSV-2 titer, indicating that the egress process of HSV-2 was also inhibited besides the packaging process. Therefore, Retro-2.1 was demonstrated to inhibit the late stages of the HSV-2 lifecycle.

Overall, Retro-2.1 was identified as an effective inhibitor of HSV-2 in vitro by a dual mechanism of action on virus entry and the late stages of infection.

\section{Discussion}

Alternative antiviral agents against HSV-2 with distinct targets from those of commonly used nucleoside analogs are greatly needed [10, 42]. Retro- 2.1 is an optimized derivative of Retro- $2^{\text {cycl }}$, which has been reported to be an inhibitor of several pathogens by interfering with the intracellular vesicle transport [19, 24]. Here, we demonstrated Retro-2.1 as an effective inhibitor of HSV-2 in cell cultures.

In this study, the antiviral activity of Retro-2.1 against HSV-2 was first identified in CPE inhibition and plaque reduction assays, with $\mathrm{IC}_{50}$ values below $7 \mu \mathrm{M}$ and an SI value of 20.88 (Table 1) which is considered to be suitable for an antiviral agent as previously reported [43], and subsequently confirmed by significant reductions in the HSV-2 protein (monitored by VP5) and DNA content as well as virus titers in a single replicative cycle (Fig. 3). The antiviral mechanisms of Retro-2.1 against HSV-2 were further explored. The clear reductions in HSV-2 DNA content as well as virus titers in the cell cultures when Retro-2.1 was applied during $5 \mathrm{~h}$ before infection or $6-18 \mathrm{~h}$ post-infection indicated that Retro-2.1 targeted both early and late stages of the HSV-2 lifecycle (Fig. 4). A dual antiviral mechanism of action was also reported in a study on the effects of SPL-2999 on both entry and late stages of the HSV-2 lifecycle [40].

A significant reduction in HSV-2 entry rather than binding rate and a clear redistribution of HSV-2 from the area near or in the nuclei to the periphery area around the cell membranes after pretreatment of the cells with Retro2.1 demonstrated that Retro- 2.1 blocked HSV-2 entry into cells in the early stages of the HSV-2 lifecycle (Fig. 5). The endocytic entry pathway of HSV-2 involves trapping of viruses by the membrane machinery, transport of viruses trapped in endocytic vesicles, and release of viruses to the cytoplasm by fusion of the virus envelope with the vesicle membranes [44, 45]. The mechanism of inhibiting HSV-2 entry into cells may be correlated with the capacity of Retro-2.1 to modulate the intracellular vesicle transport [19]. Moreover, early stage-based antivirals have significantly attracted the attention of researchers because the reduced virus entry translates to decreased replication and spread to other cells [46]. Early stage inhibitors of HSV-2 that have been reported until now mostly target virus binding to cells, either through the receptors or viral glycoproteins [44-46]. Thus, several reported entry inhibitors of HSV-2, including PM-19, PSM, Dynasore, and Retro-2.1 reported in our study may provide an alternative to HSV-2 inhibition in the early stages of infection $[36,47,48]$.

The significant reductions in HSV-2 titer in both the cell supernatants and the cells when Retro-2.1 was applied to the cells during $6-18 \mathrm{~h}$ post-infection confirmed the inhibitory effect of Retro-2.1 on the late stages of the HSV-2 
lifecycle (Fig. 6). The reductions also suggested that progeny HSV-2 packaging, which mainly takes place gradually from $5 \mathrm{~h}$ post-infection, was most likely to be blocked in the late stages [38]. Besides, as extracellular HSV-2 titer was reduced to a greater extent than that of intracellular, progeny virus egress might also be inhibited by Retro-2.1 in late stages. Progeny HSV-2 packaging begins with capsid assembly in the cell nuclei, followed by infectious enveloped HSV-2 packaging by budding the capsids into specialized vesicles derived from the trans-Golgi network to gain an envelope and an outer vesicular membrane. [2527]. The mechanism of inhibiting the late stages of the HSV-2 lifecycle may be correlated with the capacity of Retro-2.1 to modulate intracellular vesicle transport [19].

Overall, our study indicates that Retro-2.1 exerts a dual antiviral effect against HSV-2 by inhibition of the virus entry and late stages of infection. The intracellular vesicle transport involved in these processes is most likely to be inhibited, which is in agreement with previous studies on the inhibitory effects of Retro-2.1 on other pathogens [19]. Therefore, Retro-2.1 may inhibit infection at two levels in the viral lifecycle depending on the type of virus. Virus entry is blocked for adeno-associated viruses, polyomaviruses, papillomaviruses, Ebola virus and Marburg virus, whereas virus packaging or egress is blocked for poxviruses and enterovirus 71 [13, 14, 16-18, 23]. For HSV-2, both steps are blocked by Retro-2.1, as reported in this study.

As Retro-2.1 targets the host factor rather than HSV-2 itself, it is less likely for drug resistance to be developed [13]. Moreover, our findings further demonstrate the potential of Retro-2.1 to be developed as a promising broad-spectrum drug against toxins, viruses and other pathogens $[19,49]$. As a number of derivatives of Retro-2 ${ }^{\text {cycl }}$ and Retro-2.1 have been synthesized, these analogs are potential lead compounds that would contribute considerably to anti-HSV-2 drug development [13, 24, 50-52].

In conclusion, we identified the effective antiviral activity of Retro-2.1 against HSV-2 in vitro and investigated the dual mechanism of action on virus entry and late stages of the HSV-2 lifecycle. Thus, Retro-2.1 is a potential lead compound for anti-HSV-2 drug development. Virus entry as well as late stages of infection associated with intracellular vesicle transport could be antiviral targets for HSV-2.

\section{Acknowledgments}

This work was supported by a grant from the National Natural Science Foundation of China (Grant No. 31770184); a grant from the Agence Nationale de la Recherche (Grant
No. ANR-10-LABX-33); ANR grant Anti-HUS (Grant No. ANR-14-CE16-0004); and the LERMIT LabEx grant R3 RetroLeishma, Ile de France Region grant from the DIM Malinf initiative 140101, a grant from the Swedish Research Council and CEA (Grant No. K2015-99X-22877-01-6).

\section{Conflict of Interest}

The authors have no financial conflicts of interest to declare.

\section{References}

1. Whitley RJ, Kimberlin DW, Roizman B. 1998. Herpes simplex viruses. Clin. Infect. Diseases 26: 541-553; quiz 554-545.

2. Gupta R, Warren T, Wald A. 2007. Genital herpes. Lancet 370: 2127-2137.

3. Celum CL. 2004. The interaction between herpes simplex virus and human immunodeficiency virus. Herpes 11 (Suppl 1): 36A-45A.

4. Wald A, Link K. 2002. Risk of human immunodeficiency virus infection in herpes simplex virus type 2-seropositive persons: a meta-analysis. J. Infect. Dis. 185: 45-52.

5. Lehtinen M, Koskela P, Jellum E, Bloigu A, Anttila T, Hallmans $G$, et al. 2002. Herpes simplex virus and risk of cervical cancer: a longitudinal, nested case-control study in the Nordic countries. Am. J. Epidemiol. 156: 687-692.

6. Looker KJ, Gamett GP, Schmid GP. 2008. An estimate of the global prevalence and incidence of herpes simplex virus type 2 infection. Bull. World Health Organ. 86: 805-812.

7. Johnston C, Koelle DM, Wald A. 2011. HSV-2: in pursuit of a vaccine. J. Clin. Invest. 121: 4600-4609.

8. Cassady KA, Whitley RJ. 1997. New therapeutic approaches to the alphaherpesvirus infections. J. Antimicrob. Chemother. 39: $119-128$.

9. Morfin F, Thouvenot D. 2003. Herpes simplex virus resistance to antiviral drugs. J. Clin. Virol. 26: 29-37.

10. De SK, Hart JCL, Breuer J. 2015. Herpes simplex virus and varicella zoster virus: recent advances in therapy. Curr. Opin. Infect. Dis. 28: 589-595.

11. Stechmann B, Bai S-K, Gobbo E, Lopez R, Merer G, Pinchard S, et al. 2010. Inhibition of retrograde transport protects mice from lethal ricin challenge. Cell 141: 231-242.

12. Cai H, Reinisch K, Ferro-Novick S. 2007. Coats, tethers, Rabs, and SNAREs work together to mediate the intracellular destination of a transport vesicle. Dev. Cell 12: 671-682.

13. Carney DW, Nelson CDS, Ferris BD, Stevens JP, Lipovsky A, Kazakov T, et al. 2014. Structural optimization of a retrograde trafficking inhibitor that protects cells from infections by human polyoma- and papillomaviruses. Bioorg. Med. Chem. 22: $4836-4847$.

14. Nelson CDS, Carney DW, Derdowski A, Lipovsky A, Gee GV, 
O'Hara B, et al. 2013. A retrograde trafficking inhibitor of ricin and Shiga-like toxins inhibits infection of cells by human and monkey polyomaviruses. Mbio 4: e00729-13.

15. Maginnis MS, Nelson CDS, Atwood WJ. 2015. JC polyomavirus attachment, entry, and trafficking: unlocking the keys to a fatal infection. J. Neurovirol. 21: 601-613.

16. Harrison $K$, Haga IR, Pechenick Jowers T, Jasim S, Cintrat J-C, Gillet $\mathrm{D}$, et al. 2016. Vaccinia virus uses retromer-independent cellular retrograde transport pathways to facilitate the wrapping of intracellular mature virions during viral morphogenesis. J. Virol. 90: 10120-10132.

17. Sivan G, Weisberg AS, Americo JL, Moss B. 2016. Retrograde transport from early endosomes to the trans-golgi network enables membrane wrapping and egress of vaccinia virus virions. J. Virol. 90: 8891-8905.

18. Nonnenmacher ME, Cintrat J-C, Gillet D, Weber T. 2015. Syntaxin 5-dependent retrograde transport to the trans-golgi network is required for adeno-associated virus transduction. J. Virol. 89: 1673-1687.

19. Gupta N, Noel R, Goudet A, Hinsinger K, Michau A, Pons V, et al. 2017. Inhibitors of retrograde trafficking active against ricin and Shiga toxins also protect cells from several viruses, Leishmania and Chlamydiales. Chem. Biol. Int. 267: 96-103.

20. Canton J, Kima PE. 2012. Targeting host syntaxin-5 preferentially blocks Leishmania parasitophorous vacuole development in infected cells and limits experimental Leishmania infections. Am. J. Pathol. 181: 1348-1355.

21. Herweg J-A, Pons V, Becher D, Hecker M, Krohne G, Barbier J, et al. 2016. Proteomic analysis of the Simkaniacontaining vacuole: the central role of retrograde transport. Mol. Microbiol. 99: 151-171.

22. Secher T, Shima A, Hinsinger $K$, Cintrat JC, Johannes $L$, Barbier J, et al. 2015. Retrograde trafficking inhibitor of Shiga toxins reduces morbidity and mortality of mice infected with enterohemorrhagic Escherichia coli. Antimicrob. Agents Chemother. 59: 5010-5013.

23. Dai W, Wu Y, Bi J, Lu X, Hou A, Zhou Y, et al. 2017. Antiviral effects of Retro-2ycl and Retro-2.1 against Enterovirus 71 in vitro and in vivo. Antiviral Res. 144: 311-321.

24. Gupta N, Pons V, Noel R, Buisson D-A, Michau A, Johannes L, et al. 2014. (S)-N-Methyldihydroquinazolinones are the active enantiomers of Retro-2 derived compounds against toxins. ACS Med. Chem. Lett. 5: 94-97.

25. Mingo RM, Han J, Newcomb WW, Brown JC. 2012. Replication of herpes simplex virus: egress of progeny virus at specialized cell membrane sites. J. Virol. 86: 7084-7097.

26. Granzow H, Klupp BG, Fuchs W, Veits J, Osterrieder N, Mettenleiter TC. 2001. Egress of alphaherpesviruses: comparative ultrastructural study. J. Virol. 75: 3675-3684.

27. Owen DJ, Crump CM, Graham SC. 2015. Tegument assembly and secondary envelopment of alphaherpesviruses. Viruses 7: 5084-5114.

28. Bourinbaiar AS, Lee-Huang S. 1996. The activity of plant- derived antiretroviral proteins MAP30 and GAP31 against herpes simplex virus in vitro. Biochem. Biophys. Res. Commun. 219: 923-929.

29. Lund J, Sato A, Akira S, Medzhitov R, Iwasaki A. 2003. Toll-like receptor 9-mediated recognition of herpes simplex virus-2 by plasmacytoid dendritic cells. J. Exp. Med. 198: 513-520.

30. Crouch SP, Kozlowski R, Slater KJ, Fletcher J. 1993. The use of ATP bioluminescence as a measure of cell proliferation and cytotoxicity. J. Immunol. Methods 160: 81-88.

31. Pauwels R, Balzarini J, Baba M, Snoeck R, Schols D, Herdewijn P, et al. 1988. Rapid and automated tetrazoliumbased colorimetric assay for the detection of anti-HIV compounds. J. Virol. Methods 20: 309-321.

32. Brown JC, Newcomb WW. 2011. Herpesvirus capsid assembly: insights from structural analysis. Curr. Opin. Virol. 1: 142-149.

33. Yao F, Eriksson E. 2002. Inhibition of herpes simplex virus type 2 (HSV-2) viral replication by the dominant negative mutant polypeptide of HSV-1 origin binding protein. Antiviral Res. 53: 127-133.

34. Argenta DF, Silva IT, Bassani VL, Koester LS, Teixeira HF, Simoes CMO. 2015. Antiherpes evaluation of soybean isoflavonoids. Arch. Virol. 160: 2335-2342.

35. Antoine TE, Mishra YK, Trigilio J, Tiwari V, Adelung R, Shukla D. 2012. Prophylactic, therapeutic and neutralizing effects of zinc oxide tetrapod structures against herpes simplex virus type-2 infection. Antiviral Res. 96: 363-375.

36. Mues MB, Cheshenko N, Wilson DW, Gunther-Cummins L, Herold BC. 2015. Dynasore disrupts trafficking of herpes simplex virus proteins. J. Virol. 89: 6673-6684.

37. Boehmer PE, Lehman IR. 1997. Herpes simplex virus DNA replication. Annu. Rev. Biochem. 66: 347-384.

38. Koyama AH, Uchida T. 1988. Quantitative studies on the maturation process of herpes simplex virus type 1 in Vero cells. Virus Res. 10: 281-285.

39. Harden EA, Falshaw R, Carnachan SM, Kern ER, Prichard MN. 2009. Virucidal activity of polysaccharide extracts from four algal species against herpes simplex virus. Antiviral Res. 83: 282-289.

40. Gong YH, Matthews B, Cheung D, Tam T, Gadawski I, Leung D, et al. 2002. Evidence of dual sites of action of dendrimers: SPL-2999 inhibits both virus entry and late stages of herpes simplex virus replication. Antiviral Res. 55: 319-329.

41. Kalu NN, Desai PJ, Shirley CM, Gibson W, Dennis PA, Ambinder RF. 2014. Nelfinavir inhibits maturation and export of herpes simplex virus 1. J. Virol. 88: 5455-5461.

42. Brugha R, Keersmaekers K, Renton A, Meheus A. 1997. Genital herpes infection: a review. Int. J. Epidemiol. 26: 698-709.

43. Tsuchiya Y, Shimizu M, Hiyama Y, Itoh K, Hashimoto Y, Nakayama M, et al. 1985. Antiviral activity of natural occurring flavonoids in vitro. Chem. Pharm. Bull. 33: 3881-3886. 
44. Akhtar J, Shukla D. 2009. Viral entry mechanisms: cellular and viral mediators of herpes simplex virus entry. FEBS J. 276: 7228-7236.

45. Agelidis AM, Shukla D. 2015. Cell entry mechanisms of HSV: what we have learned in recent years. Future Virol. 10: $1145-1154$.

46. Hadigal S, Shukla D. 2013. Exploiting herpes simplex virus entry for novel therapeutics. Viruses 5: 1447-1465.

47. Dan K, Miyashita K, Seto Y, Fujita H, Yamase T. 2002. The memory effect of heteropolyoxotungstate (PM-19) pretreatment on infection by herpes simplex virus at the penetration stage. Pharm. Res. 46: 357-362.

48. Qiu M, Chen Y, Song S, Song H, Chu Y, Yuan Z, et al. 2012. Poly (4-styrenesulfonic acid-co-maleic acid) is an entry inhibitor against both HIV-1 and HSV infections - potential as a dual functional microbicide. Antiviral Res. 96: 138-147.
49. Schang LM. 2014. Biophysical approaches to entry inhibitor antivirals with a broad spectrum of action. Future Virol. 9: 283-299.

50. Noel R, Gupta N, Pons V, Goudet A, Garcia-Castillo MD, Michau A, et al. 2013. N-Methyldihydroquinazolinone derivatives of Retro-2 with enhanced efficacy against Shiga toxin. J. Med. Chem. 56: 3404-3413.

51. Yu S, Park JG, Kahn JN, Tumer NE, Pang Y-P. 2013. Common pharmacophore of structurally distinct smallmolecule inhibitors of intracellular retrograde trafficking of ribosome inactivating proteins. Sci. Rep. 3: 3397.

52. Craig E, Huyghues-Despointes C-E, Yu C, Handy EL, Sello JK, Kima PE. 2017. Structurally optimized analogs of the retrograde trafficking inhibitor Retro-2cycl limit Leishmania infections. PLoS Negl. Trop. Dis. 11: e0005556. 